\title{
Impact of Patient and Procedure Mix on Finances of Perinatal Centres - Theoretical Models for Economic Strategies in Perinatal Centres
}

\author{
Einflüsse des Leistungsspektrums auf die Erlössituation und Finanzierbarkeit von Perinatalzentren Level I - \\ theoretische Modelle zur wirtschaftlichen Leistungsprogrammplanung von Perinatalzentren
}

Authors

Affiliation
T. Hildebrandt, F. Kraml, S. Wagner, C. C. Hack, F. C. Thiel, S. Kehl, M. Winkler, W. Frobenius,

F. Faschingbauer, M. W. Beckmann, M. P. Lux

${ }^{1}$ Department of Gynecology and Obstetrics, Erlangen University Hospital, Erlangen
Key words

- perinatal centres

- financing

- DRG system

costs

rate of caesarean sections

\section{Schlüsselwörter}

- Perinatalzentren

- Finanzierung

- DRG-System

- Kosten

- Sectio-Rate

\section{received 20.5.2013 \\ revised $\quad 30.5 .2013$ \\ accepted 1.6.2013}

\section{Bibliography}

DOI http://dx.doi.org/ 10.1055/s-0033-1350650

Geburtsh Frauenheilk 2013; 73:

783-791 @ Georg Thieme

Verlag KG Stuttgart · New York ISSN 0016-5751

\section{Correspondence}

\section{Dr. Thomas Hildebrandt}

Universitätsklinikum Erlangen

Frauenklinik

91054 Erlangen

thomas.hildebrandt@

uk-erlangen.de

\section{Abstract \\ $\nabla$}

Introduction: In Germany, cost and revenue structures of hospitals with defined treatment priorities are currently being discussed to identify uneconomic services. This discussion has also affected perinatal centres (PNCs) and represents a new economic challenge for PNCs. In addition to optimising the time spent in hospital, the hospital management needs to define the "best" patient mix based on costs and revenues.

Method: Different theoretical models were proposed based on the cost and revenue structures of the University Perinatal Centre for Franconia (UPF). Multi-step marginal costing was then used to show the impact on operating profits of changes in services and bed occupancy rates. The current contribution margin accounting used by the UPF served as the basis for the calculations. The models demonstrated the impact of changes in services on costs and revenues of a level 1 PNC. Results: Contribution margin analysis was used to calculate profitable and unprofitable DRGs based on average inpatient cost per day. Nineteen theoretical models were created. The current direct costing used by the UPF and a theoretical model with a $100 \%$ bed occupancy rate were used as reference models. Significantly higher operating profits could be achieved by doubling the number of profitable DRGs and halving the number of less profitable DRGs. Operating profits could be increased even more by changing the rates of profitable DRGs per bed occupancy. The exclusive specialisation on pathological and highrisk pregnancies resulted in operating losses. All models which increased the numbers of caesarean sections or focused exclusively on c-sections resulted in operating losses.

Conclusion: These theoretical models offer a basis for economic planning. They illustrate the enormous impact potential changes can have on the operating profits of PNCs. Level 1 PNCs require

\section{Zusammenfassung \\ $\nabla$}

Einleitung: In der Diskussion über die Kostenund Erlösstruktur von Krankenhäusern mit der Definition von Behandlungsschwerpunkten und Identifikation von unwirtschaftlichen Leistungen stehen auch Perinatalzentren (PNZ) vor neuen gesundheitsökonomischen Herausforderungen. Neben der Optimierung der Verweildauer ist hierbei auch der jeweilige „beste“ Patientenmix in Abhängigkeit von den zu erzielenden Erlösen und Deckungsbeiträgen für das Krankenhausmanagement entscheidend.

Methodik: Am Beispiel der Kostenstruktur des Universitäts-Perinatalzentrum Franken (UPF) wurden theoretische Kalkulationsmodelle berechnet und bei Veränderung des Leistungsspektrums sowie der Kapazitätsauslastung die Veränderungen auf die Erlössituation dargestellt. Als Grundlage der Berechnungen diente die reale Deckungsbeitrags-(DB-)Rechnung des UPF. Im Rahmen der modellhaften Deckungsbeitragsrechnung konnten Einflüsse auf die Kosten-Erlös-Situation bei verändertem Leistungsspektrum eines PNZ des Level I berechnet werden.

Ergebnisse: Unter Zuhilfenahme des durchschnittlichen DB I pro Pflegetag kann in gewinnund verlustbringende DRGs unterschieden werden. Insgesamt wurden 19 theoretische Modelle erstellt. Als Bezugsmodell dienen die reale Deckungsbeitragsrechnung des UPF sowie das Modell bei 100\%iger Bettenauslastung. Mittels Verdopplung der Anteile gewinnbringender DRGs und Halbierung der Anteile weniger lohnenswerter DRGs kann das Betriebsergebnis deutlich verbessert werden. Durch eine möglichst gewinnbringende Umverteilung der verschiedenen geleisteten Prozentzahlen je DRG an der Gesamtbettenauslastung auf andere DRGs kann das positive Betriebsergebnis darüber hinaus weiter gesteigert werden. Eine Spezialisierung auf ausschließlich pathologische Schwangerschaften ergibt ein ne- 
high bed occupancy rates and a profitable patient mix to cover the extremely high costs incurred due to the services they are legally required to offer. Based on our theoretical models it must be stated that spontaneous vaginal births (not caesarean sections) were the most profitable procedures in the current DRG system. Overall, it currently makes economic sense for level I PNCs to treat as many low-risk pregnancies and neonates as possible to cover costs. gatives Betriebsergebnis. Modelle mit forcierter oder ausschließlicher Konzentration auf Sectiones im Leistungsangebot führen allesamt zu einem negativen Betriebsergebnis.

Schlussfolgerung: Mittels der theoretischen Modelle sind Planungen aus betriebswirtschaftlicher Sicht möglich. Es wird deutlich, welchen z.T. enormen Veränderungen ein Betriebsergebnis eines PNZ unterliegen kann. PNZ Level I benötigen insbesondere eine hohe Auslastung ihrer Bettenkapazitäten und einen gewinnbringenden Fallmix, um die durch die gesetzlichen Anforderungen sehr hohen Kosten decken zu können. Zudem kann auf Basis der theoretischen Modelle konstatiert werden, dass es die vaginalen Geburten (nicht Sectiones) sind, welche im aktuellen DRG-System kostendeckend abgebildet sind. Insgesamt erscheint es für PNZ Level I ökonomisch sinnvoller zu sein, möglichst viele Schwangerschaften und Neugeborene mit einem niedrigen Risikoprofil zu behandeln, um die Kosten decken zu können.

\section{Introduction}

$\nabla$

The German healthcare system has been undergoing deep structural and cultural changes in recent years. The German legislative body has imposed a number of new general conditions which should make medical treatments and the costs and revenues of hospitals more transparent as well as encouraging hospitals to be more cost-effective and profitable. Given the increased competitive pressures, the assumption is that around $30 \%$ of hospitals in Germany will have to close in the next 10 years [1-3].

For this reason, health economic evaluations have increasingly honed in on the finances of perinatal centres. If a centre intends to maintain its maternity department, the first consideration must be to determine which best level of care would best suit the hospital (levels I-IV as defined by the criteria of the German Joint Federal Committee) [4]. Defining the right treatment priorities and making decisions about the range of profitable and unprofitable treatments offered by the centre will become increasingly important in the years to come [5].

To remain competitive and improve a centre's profitability it will be necessary to optimise the time patients spend in hospital. Reducing the number of acute beds is one way of dealing with the increased cost pressures as the provision of acute beds involves high fixed costs $[6,7]$. It is essential that hospital managements are aware of the most "cost-effective" mix of patients and procedures for their facility together with the revenues and contribution margins $[8,9]$. Numerous hospitals have become specialist centres offering more complex procedures and "higher value" DRGs (Diagnosis Related Groups) in the hope of achieving higher revenues [8]. Whether this strategy can be recommended for perinatal centres from a health economic standpoint requires closer scientific analysis. Level I perinatal centres are centres offering maximum medical care and, in principle, they are not permitted to reject any cases. Nevertheless, using certain marketing and cooperation strategies it is possible to regulate the patient mix and influence the case numbers receiving various treatments while offering the same range of services or, in the event of a particularly loss-making patient mix, to negotiate specific additional charges with funding agencies.

In addition to the actual numbers of cases, the type of DRG plays a very important role for perinatal centres, as cases can be very heterogeneous, ranging from women with preterm premature rupture of membranes in the 28th week of gestation who require in-hospital bed rest to spontaneous onset of labour at term fol- lowed by delivery without complications with the mother only remaining in hospital for one day [10].

Perinatal centres are also obliged to comply with the requirements prescribed by the Federal Joint Committee and these requirements involve additional resources and costs. Physicians and nursing staff must be present at all times in delivery units and emergency units; a neonatologist must always be on standby, an obstetrician specialised in special obstetrics and perinatal medicine must always be on call. There are also a number of guidelines on infrastructure; for example, the neonatal intensive care unit must be in the immediate vicinity of the delivery unit and operating room and the neonatal intensive care unit must have at least six intensive care beds $[4,11]$.

These detailed and cost-intensive requirements and the current discussion about the minimum size of facilities mean that perinatal medical care currently faces important challenges which will require carefully considered planning and management decisions. A detailed knowledge of the potential impact of the different treatments offered is essential for decision-making. The following questions, which were investigated in the present study using theoretical models, are of particular interest when a hospital management is considering how to secure the long-term survival of their hospital:

- What is the impact of different DRGs or services and treatments on operating profits?

- Does it make more economic sense to treat more high-risk patients or is it better to treat more patients with a lower risk profile?

- What economic impact do different obstetrical procedures have; in particular, how does spontaneous birth compare to caesarean section?

- What is the effect of fully utilising all bed capacities and operating room minutes and what will occur if some of the capacities remain unused?

\section{Material and Methods \\ $\nabla$}

The data of the 2009 multistage contribution margin accounting of the University Perinatal Centre for Franconia (UPF) were used as the basis for all theoretical costing models [12].

When calculating capacity constraints, the P-DRGs (neonates) were not included in the capacity of 36 beds available in the obstetrical department of the University Hospital Erlangen. Only 
the DRGs O01A-O40Z were included in the OP-DRGs (operative DRGs) (० Table 1).

Unless otherwise stated in the brief description of the individual theoretical model, the real number of days in hospital was established for each respective DRG and the maximum number of cases was calculated for each DRG based on the total number of days stayed in hospital in 2009.

The total number of days stayed in hospital and the total OR (operating room) minutes were defined in the model as the capacity constraints. The percentage each individual DRG contributed to the total number of days in hospital and the total number of OR minutes in 2009 was calculated. In the next step, the maximum number of cases which could be treated if only this DRG was treated was calculated for every DRG based on the average number of days spent in hospital for every individual DRG, taking the calculated capacity constraint of 13140 hospital days into account. If it was assumed that surgical procedures were performed in the operating room of the UPF delivery unit for 10 hours every weekday of the year and 4 hours per day on weekends and public holidays, the potential total OR capacity was calculated as 176880 OR minutes. If, instead, it was assumed that surgical procedures were carried out every day of the year, 24 hours a day, the OR capacity was 525600 OR minutes.

Subsequently the utilisation percentage for the capacity constraint was established for every DRG in the different theoretical

Table 1 DRGs arranged according to profitable and loss-generating treatments (middle grey : DRGs which are profitable for the perinatal centre, dark grey : DRGs which are less profitable for the perinatal centre, light grey : midway position between profitable and less profitable DRGs = DRGs with no effect on revenues).

\begin{tabular}{|c|c|c|}
\hline DRG & Brief description of the DRG & $\begin{array}{l}\text { Average } \mathrm{CM} \text { I per DRG case } \\
\text { per inpatient day in } €\end{array}$ \\
\hline O01A & $\begin{array}{l}\text { Caesarean section with several complicating diagnoses, up until the end of the } 25 \text { th week of gestation } \\
\text { or with intrauterine therapy or complicating constellation }\end{array}$ & 193.00 \\
\hline O01B & $\begin{array}{l}\text { Caesarean section with several complicating diagnoses, 26th to 33rd completed week of gestation, } \\
\text { without intrauterine therapy, no complicating constellation }\end{array}$ & 269.49 \\
\hline O01C & $\begin{array}{l}\text { Caesarean section with several complicating diagnoses, > 33rd week of gestation, without intrauterine therapy, } \\
\text { no complicating constellation or with complicating diagnosis }\end{array}$ & 333.76 \\
\hline O01D & $\begin{array}{l}\text { Secondary caesarean section with several complicating diagnoses, > 33rd week of gestation, } \\
\text { without intrauterine therapy, no complicating constellation or with complicating diagnosis }\end{array}$ & 371.89 \\
\hline O01E & Secondary caesarean section with complicating diagnosis, > 33rd week of gestation, no complex diagnosis & 376.38 \\
\hline O01F & $\begin{array}{l}\text { Caesarean section without complicating diagnosis, > 33rd week of gestation, 33rd week of gestation, } \\
\text { no complex diagnosis }\end{array}$ & 448.28 \\
\hline O02A & $\begin{array}{l}\text { Vaginal delivery with complicated OR procedure, up to 33rd week of gestation or with intrauterine therapy } \\
\text { or complicating constellation }\end{array}$ & 535.39 \\
\hline O02B & $\begin{array}{l}\text { Vaginal delivery with complicated OR procedure, }>33 \text { SSW, without intrauterine therapy, } \\
\text { no complicating constellation }\end{array}$ & 384.85 \\
\hline $\mathrm{O} 03 \mathrm{Z}$ & Ectopic pregnancy & 430.05 \\
\hline $\mathrm{O} 04 \mathrm{Z}$ & Admission to hospital after delivery or miscarriage requiring OR procedure & 191.89 \\
\hline O05A & Cerclage and cervical cerclage & 611.44 \\
\hline O05B & Certain OR procedures during pregnancy without cerclage, without cervical cerclage & 518.14 \\
\hline O06B & Intrauterine therapy of the foetus without laser therapy & 263.51 \\
\hline $\mathrm{O} 40 \mathrm{Z}$ & Miscarriage with dilation and curettage, aspiration curettage or hysterotomy & 387.62 \\
\hline O60A & $\begin{array}{l}\text { Vaginal delivery with several complicating diagnoses, at least one of them serious, up to 33rd week of gestation } \\
\text { or with complicating constellation }\end{array}$ & 454.18 \\
\hline O60B & $\begin{array}{l}\text { Vaginal delivery with several complicating diagnoses, at least one of them serious, > 33rd week of gestation, } \\
\text { no complicating constellation }\end{array}$ & 391.73 \\
\hline O60C & Vaginal delivery with serious or moderately serious complicating diagnosis & 376.64 \\
\hline O60D & Vaginal delivery without complicating diagnosis & 416.56 \\
\hline 0612 & Admission to hospital after delivery or miscarriage without OR procedure & 250.26 \\
\hline $062 Z$ & Imminent miscarriage & 365.45 \\
\hline $063 Z$ & Miscarriage without dilation and curettage, aspiration curettage or hysterotomy & 236.92 \\
\hline O64A & Ineffective contractions, more than one day of hospitalisation & 208.18 \\
\hline O64B & Ineffective contractions, one day of hospitalisation & 282.43 \\
\hline O65A & Other pre-birth hospital admissions with extremely serious or serious CC & 98.76 \\
\hline О65B & Other pre-birth hospital admissions without extremely serious or serious CC & 176.17 \\
\hline P60A & Neonate, died $<5$ days after admission without significant OR procedure & 2041.92 \\
\hline P66C & $\begin{array}{l}\text { Neonate, weight at admission } 2000-2499 \mathrm{~g} \text { without significant OR procedure, no ventilation }>95 \mathrm{~h} \text {, } \\
\text { with other problems }\end{array}$ & 1276.11 \\
\hline P66D & $\begin{array}{l}\text { Neonate, weight at admission } 2000-2499 \mathrm{~g} \text { without significant OR procedure, no ventilation }>95 \mathrm{~h} \text {, } \\
\text { without problems or multiple births, weight at admission }>2499 \mathrm{~g}\end{array}$ & 284.11 \\
\hline P67B & Neonate, weight at admission $>2499 \mathrm{~g}$ without significant OR procedure, no ventilation $>95 \mathrm{~h}$, with serious problem & 902.76 \\
\hline P67C & Neonate, weight at admission $>2499 \mathrm{~g}$ without significant OR procedure, no ventilation $>95 \mathrm{~h}$, with other problem & 449.17 \\
\hline P67D & $\begin{array}{l}\text { Newborn singleton, weight at admission }>2499 \mathrm{~g} \text { without OR procedure, no ventilation }>95 \mathrm{~h} \text {, no serious problem, } \\
\text { no other problem }\end{array}$ & 203.80 \\
\hline
\end{tabular}

DRG = Diagnosis Related Groups; CM = contribution margin; O01A-P67D = DRGs relevant for perinatal centres; OR procedure = operating room procedure, significant intervention as defined by the DRG system; CC = complications and/or co-morbidities 
models; the capacity constraint was assumed to be $100 \%$, making it possible to compare the models to one another.

Once the case numbers for the theoretical models had been established, data from the calculations for the real model of the UPF were used again. The total number of days in hospital was calculated by multiplying the ascertained number of cases with the average number of days in hospital per DRG case. The total OR time for every DRG was calculated analogously. The case numbers for every DRG were multiplied with the average contribution margin I for every DRG case; the results were then added up and the total was the contribution margin I.

In the next step, the UPF's fixed costs in 2009 were included. The calculated contribution margin II for in-hospital (DRG) services was added to the contribution margin II for outpatient services (prenatal outpatient clinics and pregnancy clinics of the UPF) for 2009. These figures were not modified in the theoretical models. The general and administrative lump sum costs amounting to $19.3 \%$ of all UPF revenue were deducted from the sum of the two contribution margins II.

This study did not examine the cost-revenue situation for outpatients and outpatient services as the theoretical models only focussed on the impact of various combinations of in-hospital treatments. The economic benefits and disadvantages of outpatient management structures have been examined elsewhere in more detail in a real model [12].

In principle, the ratio between the number of births and the P-DRG payments should be the same in the theoretical models as in the real model. In 2009, there were 2143 births in the perinatal centre and 1615 P-DRGs; this corresponds to a ratio of births to P-DRGs of 1.33. The number of P-DRGs in the theoretical models was therefore calculated by dividing the number of births in the respective model by the ratio of births to P-DRGs calculated for the year 2009.

To adjust the operating income to the potential over- or underutilisation of beds it was necessary to calculate how many beds would be required for different mixes of cases. Personnel costs are step costs which do not increase or decrease in proportion to bed occupancy rates but increase or decrease stepwise. Nevertheless, for the purposes of simplification, in the theoretical models changes in fixed costs were calculated as proportional changes based on the number of additional beds required.

\section{Results}

$\nabla$

The average contribution margin I per inpatient day for each DRG case can be calculated using the average contribution margin I together with the average time spent in hospital for each DRG. Using the respective real costs, DRGs can be divided into profitable and loss-making DRGs. This information obtained from theoretical models is highly relevant when considering which treatments to offer.

The most profitable DRGs were spontaneous births occurring at term and without complications (O60D), vaginal births with complicating OR procedures (an operating room procedure was a significant intervention as defined by the DRG system) or several complicating diagnoses up until the 33rd week of gestation (O02A, 060A) as well as caesarean sections (c-sections) without complicating diagnoses performed after the 33rd week of gestation (O01F). In the UPF, the following DRGs were classified as less profitable when the real costs were included: caesarean section with several complicating diagnoses (001A-001C), vaginal deliv- ery with complicated OR procedure after the 33rd week of gestation (O02B) and prenatal maternal admissions to hospital (O64A, 064B, 065A, 065B). 0 Table 1 shows the respective contribution margin I for every DRG case per inpatient day. The brief description provides a summary of the key points for each DRG. DRGs classed as profitable are highlighted in middle grey, unprofitable DRGs highlighted in dark grey. All non highlighted DRGs were neither profitable nor definitely loss-making.

A total of 19 theoretical models were compiled ( Table 2). Fifteen of these models could be compared directly with each other as they all featured bed occupancy rates of $100 \%$. All models were below the potential and realistic surgical capacity limit of 176880 surgical minutes, with the exception of model 0 , which was slightly higher with 194296 surgical minutes. As the capacity constraints were comparable it was assumed that the fixed costs were also virtually identical.

The models "2009" and "2009 100\%" were the reference models (highlighted in light grey in $\triangle$ Table 2). The model 2009 calculated the operating profits and losses, using the same bed occupancy rates and share of bed occupancy rates per DRG as in 2009. The cost data and revenues on which the model is based and the potential factors which influence the basic model could have been presented and discussed elsewhere [12].

The model 2009 100\% was particularly important as it served as a baseline with which to compare other theoretical models with $100 \%$ bed occupancy rates. If the operating result of a theoretical model with a $100 \%$ occupancy rate of available beds was shown to be higher (highlighted in middle grey in $\triangle$ Table 2) than the operating result calculated for the model 2009 100\%, this model would recommend itself to the hospital management from an economic standpoint (without taking account of the medical, ethical and legal issues involved). However, if the operating result of a theoretical model was much below that calculated for 2009 $100 \%$ (highlighted in dark grey in 0 Table 2 ), the range of services provided would need to be reviewed and steps would need to be taken to amend the range of services provided, if possible.

After adjusting the fixed costs proportionately to take account of the over- and under-utilisation of the capacity constraint "inpatient days", an operating profit amounting to $€ 108665.02$ was calculated for model D, an operating loss of $€-1484022.70$ for model $\mathrm{H}$ and an operating profit of $€ 3109527.44$ for model Q. Based on the operating profit of $€ 1742922.43$ generated by doubling the share of profitable DRGs and halving the proportion of less profitable DRGs, the case mix of model M was best. The redistribution of the percentages of each DRG of the 2009 bed occupancy rates of the UPF to other DRGs according to profitability in Model O led to an operating profit of $€ 3221534.33$.

As the simulations showed that the capacity constraint "inpatient days" was the most significant factor, it was important to calculate how much operating results depended on bed occupancy rates. It was assumed that the fixed costs remained the same for all bed occupancy rates, whether bed occupancy rates were $100 \%$ or not. This meant that if services and treatments remained the same, there was a linear relation between bed occupancy rates and operating results ( Table 3 ). If the bed occupancy rate was only $50 \%$, this generated an operating loss for the UPF of $€-1285437.66$. A bed occupancy rate of $76.66 \%$ constituted the threshold between profit and loss with an operating profit of $€ 0$. If the bed occupancy rate was $79.70 \%$ (as recorded for 2009) the UPF achieved an operating profit of $€ 145787.38$. However, this figure does not factor in certain costs, e.g. that 2 medical specialists are permanently on call to ensure 24 hour readiness includ- 
Table 2 Overview of theoretical models and their results (light grey : real reference models [real model 2009 as well as possible real operational results at full capacity utilisation]; dark grey [ : less profitable and loss-making models compared to real cost models; middle grey : more profitable models compared to real cost models).

\begin{tabular}{|c|c|c|c|c|}
\hline Model & Brief description of model & $\begin{array}{l}\text { Bed occu- } \\
\text { pancy (\%) }\end{array}$ & $\begin{array}{l}\text { Surgical } \\
\text { minutes }\end{array}$ & $\begin{array}{l}\text { Operating profits } \\
\text { or losses }(€)\end{array}$ \\
\hline 2009 & Bed occupancy rate the same as in 2009 , same mix of cases, no P-DRG subventions & $79.70 \%$ & 73090 & 145787.38 \\
\hline $2009100 \%$ & 2009 model with $100 \%$ bed occupancy rate & $100.00 \%$ & 91700 & 1124999.15 \\
\hline A & No births, no P-DRGs & $100.00 \%$ & 80611 & -1739546.56 \\
\hline B & $\begin{array}{l}\text { All pregnancies or children who are only slightly pathological or not pathological at all } \\
\text { are turned away }\end{array}$ & $100.00 \%$ & 142465 & -769041.28 \\
\hline C & Only less profitable DRGs carried out & $100.00 \%$ & 34364 & -638621.25 \\
\hline D & $\begin{array}{l}\text { Surgical capacity ( } 176880 \text { minutes) distributed across all surgical DRGs; distribution } \\
\text { of DRGs according to the share of the respective DRG in the surgical minutes recorded } \\
\text { for } 2009 \text {; no other DRGs; number of beds could be reduced by } 6\end{array}$ & $84.42 \%$ & 176880 & -503067.48 \\
\hline $\mathrm{E}$ & $\begin{array}{l}\text { Equal distribution of all bed capacities used in } 2009 \text { for deliveries across the } 6 \text { different } \\
\text { O01 DRGs (c-sections); bed occupancy rates for remaining DRGs remain the same }\end{array}$ & $100.00 \%$ & 135656 & -75948.71 \\
\hline $\mathrm{F}$ & No P-DRGs & $100.00 \%$ & 91700 & -36074.87 \\
\hline G & $\begin{array}{l}\text { Only prenatal DRGs O64A/B and O65A/B and caesarean sections; the same proportion } \\
\text { of P-DRGs as in } 2009\end{array}$ & $100.00 \%$ & 144122 & 319984.76 \\
\hline $\mathrm{H}$ & $\begin{array}{l}\text { Surgical capacity ( } 176880 \text { minutes) shared out completely and evenly ( } 16.67 \%) \text { across } \\
\text { the } 6 \text { different c-section DRGs; no other DRGs; } 20 \text { additional beds required which increases } \\
\text { fixed costs }\end{array}$ & $155.90 \%$ & 176880 & 555085.64 \\
\hline I & Only non-surgical DRGs & $100.00 \%$ & 0 & 1170873.41 \\
\hline J & $\begin{array}{l}\text { Cf. models } \mathrm{E} \text { and } \mathrm{N} \text {; instead of the O01/O02 DRGs, this model includes O60 DRGs } \\
\text { (vaginal deliveries) }\end{array}$ & $100.00 \%$ & 13092 & 1204986.82 \\
\hline K & $\begin{array}{l}\text { Cf. model G; instead of the caesarean sections, this model includes O60 DRGs } \\
\text { (vaginal deliveries) }\end{array}$ & $100.00 \%$ & 0 & 1214574.84 \\
\hline $\mathrm{L}$ & All pregnancies and children with pathologies turned away & $100.00 \%$ & 72956 & 1415465.45 \\
\hline M & $\begin{array}{l}\text { Share of bed occupancy rates of profitable DRGs are doubled, share of less profitable DRGs } \\
\text { are halved; adjustment of calculated proportion of } 100 \% \text { bed occupancy rate; } \\
\text { same proportion of P-DRGs as in } 2009\end{array}$ & $100.00 \%$ & 96038 & 1742922.43 \\
\hline $\mathrm{N}$ & $\begin{array}{l}\text { Cf. models E and J; instead of O01 and O60 DRGs, this model includes O02 DRGs } \\
\text { (vaginal deliveries with complicating OR procedure) }\end{array}$ & $100.00 \%$ & 162377 & 3133122.76 \\
\hline $\mathrm{O}$ & $\begin{array}{l}\text { Proportion per DRG of the capacity constraint "inpatient days" redistributed across } \\
\text { other DRGs as profitably as possible }\end{array}$ & $100.00 \%$ & 194296 & 3221534.33 \\
\hline$P$ & $\begin{array}{l}\text { cf. model C, instead of the less profitable and loss-making DRGs this model includes only } \\
\text { the most profitable DRGs }\end{array}$ & $100.00 \%$ & 92918 & 5108788.48 \\
\hline Q & $\begin{array}{l}24 \text { OR hours in the delivery room per day ( } 525600 \text { surgical minutes per year); } \\
\text { only caesarean sections and P-DRGs; total of } 63 \text { additional beds required }\end{array}$ & $275.01 \%$ & 525600 & 9532718.69 \\
\hline
\end{tabular}

DRG = Diagnosis Related Groups; P-DRG = paediatric DRG

Table 3 Changes in operating results depending on bed occupancy rates if the fixed costs remain the same.

\begin{tabular}{|c|c|c|c|c|c|}
\hline $\begin{array}{l}\text { Total bed occupancy } \\
\text { rates (\%) }\end{array}$ & $\begin{array}{l}\text { Total length of stay } \\
\text { in hospital (days) }\end{array}$ & $\begin{array}{l}\text { Total surgical time } \\
\text { (minutes) }\end{array}$ & $\begin{array}{l}\text { CM I at the } \\
\text { DRG level }(€)\end{array}$ & $\begin{array}{l}\text { CM II at the } \\
\text { DRG level }(€)\end{array}$ & $\begin{array}{l}\text { Operating result for } \\
\text { the UPF (CM III) (€) }\end{array}$ \\
\hline $50 \%$ & 6570 & 45850 & 3172758.60 & -497636.40 & -1285437.66 \\
\hline $70 \%$ & 9198 & 64190 & 4441417.45 & 771022.45 & -321602.28 \\
\hline $71 \%$ & 9330 & 65107 & 4504665.14 & 834270.14 & -273553.65 \\
\hline $75 \%$ & 9855 & 68775 & 4759137.90 & 1088742.90 & -80214.04 \\
\hline $76.66 \%$ & 10074 & 70299 & 4864791.76 & 1194396.76 & 57.54 \\
\hline $79.70 \%$ & 10474 & 73090 & 5056630.76 & 1386235.76 & 145787.38 \\
\hline $85 \%$ & 11169 & 77945 & 5393837.81 & 1723442.81 & 401989.91 \\
\hline $95 \%$ & 12483 & 87115 & 6028537.73 & 2358142.73 & 884193.86 \\
\hline $100 \%$ & 13140 & 91700 & 6345503.71 & 2675108.71 & 1124999.15 \\
\hline $105 \%$ & 13797 & 96285 & 6663237.65 & 2992842.65 & 1366397.82 \\
\hline $120 \%$ & 15768 & 110041 & 7614176.04 & 3943781.04 & 2088844.95 \\
\hline
\end{tabular}

$\mathrm{CM}=$ contribution margin; DRG = Diagnosis Related Groups

ing coverage during vacation times and other downtimes, the impact of interdisciplinary case conferences, the synergies achieved through the shared services of surgical nurses, gynaecologists and obstetricians, etc. [12].

In general, a change in bed occupancy rates of one percentage point resulted in a change in operating results of about $€ 48000$.
This meant that if the UPF had a bed occupancy rate of $100 \%$, the operating profit for the UPF would be $€ 1124999.15$. If the UPF was able to utilise beds in other hospital wards of the Gynaecology Department of Erlangen University Hospital and thus achieve a bed occupancy rate of $120 \%$ without being saddled with the additional fixed costs, it would be possible to achieve a profit of 
$€ 2088844.95$ while offering the same services and treating the same case mix. Such a capacity overload of bed occupancy rates could also be achieved by discharging a patient and admitting another patient on the same day for the same bed. The direct relationship between operating results, based on the real model, and bed occupancy rates is shown in $\bullet$ Fig. 1.

\section{Discussion \\ $\nabla$}

Given the financial problems the German healthcare system faces with the constantly increasing pressures to reform and adapt, the agreements on minimum case numbers and on the quality of structures, processes and outcomes, the issue how the services can be financed is becoming ever more important. Perinatal centres must comply with the criteria determined by the Joint Federal Committee which categorises the centres into 4 different levels of care (levels I-IV). Because of the high demands placed on them and the high levels of staffing and financial resources required, level I perinatal centres are under particularly high financial pressure. It is therefore important that the management can distinguish between profitable and loss-making DRGs and, where possible, take measures accordingly [13].

The fact that even obstetric departments with an inadequate infrastructure and consistently low numbers of births still continue to operate would appear to indicate that obstetric services are basically always profitable. However, a more careful analysis shows that only certain services are financially viable in obstetrics, and that the refinancing of invasive obstetric interventions within the DRG system does not always cover costs [14]. Local political considerations often also play a role by providing municipal subventions for loss-making obstetric facilities to ensure their continued existence as this can be the only way in certain districts of ensuring that women can give birth locally.

The theoretical models developed for this study are based on real figures. They show that even slight changes in bed occupancy rates and in the types of services offered can quickly result in considerable losses, even in previously profitable level I perinatal centres. It is therefore important to consider the impact of some factors which hospitals cannot control, for example the patient's choice of hospital. Particularly in obstetrics, recommendations made by the patients' gynaecologist or general practitioner are less important, and word-of-mouth comments and recommendations by friends and acquaintances play a far more significant role ("labour room tourism") $[15,16]$.

The theoretical models were developed as a means of examining several issues in more detail. First of all, it was shown that the number of cases treated and the bed occupancy rate can have an enormous impact on revenues. In the real model, the UPF had a bed occupancy rate of $79.70 \%$, a figure very close to the threshold of $77 \%$, the point at which operating profits tipped over into operating losses. In practice, this means that high numbers of cases must be viewed as very important for perinatal centres. But the range of services provided also had an enormous impact. In the different models the operating results calculated for bed occupancy rates of $100 \%$ ranged from operating losses of $€-1739546.56$ to operating profits of $€ 5108788.48$. This clearly shows how important the range of services is for costs and revenues. The fact, demonstrated in this paper, that under the current DRG system level I perinatal centres are only financially viable under certain circumstances was already pointed out in the analysis by Seelbach-Göbel [13] which only analysed DRGs which

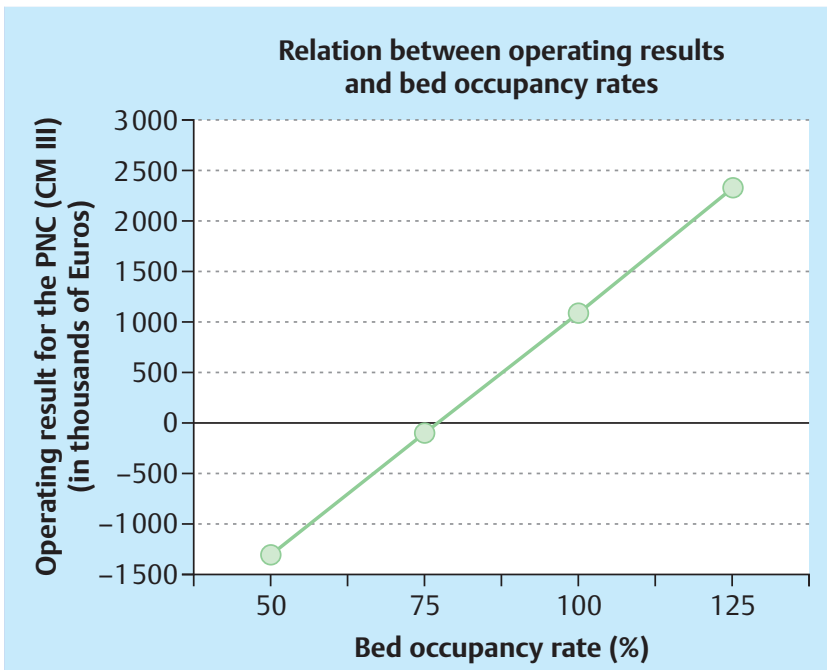

Fig. 1 Relation between operating results and bed occupancy rates (PNC = perinatal centre; $\mathrm{CM}$ = contribution margin).

ended with the birth of the baby. The level I perinatal centre was only able to achieve an operating profit because $46.95 \%$ of births were DRG O60D, $16.37 \%$ were DRG O60C and $4.89 \%$ were DRG O60B. These were not caesarean sections but vaginal deliveries without complications. They were the only obstetric services where the figure calculated by InEK (Institute for System of Hospital Remuneration) was higher than the actual costs incurred by the perinatal centre. DRG 001A, which generates by far the highest losses, amounting only to $0.30 \%$ and therefore only played a marginal role in the overall number of births recorded in the perinatal centre.

This study also selected and combined those services which would most increase the hospital's operating profits. A number of services currently offered were scrapped and the contributions of certain services to full capacity were redistributed to achieve the most profitable mix. Model P, for example, increased the operating profit from $€ 1124999.15$ to $€ 5108788.48$ at a bed occupancy rate of $100 \%$.

Model A showed that the operating profits of perinatal centres depend very much on the number of births. The 2009 case mix of the UPF with a bed occupancy rate of $100 \%$ resulted in an operating profit of $€ 1124999.15$. Model A used the same case mix and bed occupancy rate but excluded births or P-DRGs and generated a loss of $€-1739546.56$. This model did not take into account that children are born in every perinatal centre and that certain minimum numbers of births are required for every level I perinatal centre. But the simulation clearly showed that DRGs which do not immediately end with the birth of the child do not adequately cover the average costs incurred by a level I perinatal centre. The lack of funding for perinatal centres illustrated in model A could constitute a serious financial threat for German obstetric clinics if the number of births continues to drop and obstetrical developments in Germany follow the same path as in the Netherlands, where 30\% of births in 2004 were home births [17].

Because of the higher relative weight of c-sections and the resulting higher revenues it has occasionally been suggested that perinatal centres can only cover their costs if they increase the rates of caesarean sections [18-20]. Heer et al. raised concerns about 
whether elective caesarean sections covered their own costs in addition to those of vaginal deliveries [21]. The suspicion of Hornemann et al. [18] that vaginal deliveries were being subsidised by primary caesarean sections was based on the fact that their study did not take the high stand-by costs in obstetrics into account. Only personnel costs which could be directly attributed to the respective mode of delivery included in their analysis. As also pointed out by Schwenzer et al. [22], even staffing costs which arise without a specific birth event must be allocated to the births. Seelbach-Göbel [13] also commented that disregarding the costs of non-medical infrastructure distorted the picture, as these costs generally amounted to $25-30 \%$ of the total costs of a perinatal centre.

All over the world the numbers of caesarean sections have been increasing for several years. Germany is in the higher midrange with a rate of $28.5 \%[23,24]$. One reason cited for the increased rates is that they allow patients and physicians to plan and control the birth better. Another potential reason discussed in the literature is the questionable economic benefit compared to spontaneous deliveries. An analysis by the French Association of Hospitals published in 2008 showed that c-section rates were higher in private hospitals than in public hospitals, for example university hospitals, although the latter provide care for more high-risk pregnancies, which could be expected to lead to higher rates of caesarean sections [25]. According to Feige [20], only $2-3 \%$ of caesarean sections are so-called "sections on demand", done at the request of the patients themselves. Based on these figures and on the fact that caesarean sections are medically indicated in only $15-20 \%$ of cases, he deduced that around $10-15 \%$ of caesarean sections are done at the request of physicians.

Based on our calculations, if all relevant DRGs were compared directly, increasing the rate of caesarean sections brought no financial benefits. We based this assessment on the average contribution margin I per DRG and inpatient day, in other words, on the remaining sum which covers the fixed costs after all variable costs attributable to a DRG per inpatient day have been subtracted. The average figure for all caesarean sections (DRGs O01A-F) was $€ 332.13$, irrespective of the respective number of cases, while the average figure for all vaginal births (DRGs 002A/ $B, 060 A-D)$ was $€ 426.56$. After subjecting these figures to detailed analysis we found that the difference remained even when the relevant DRGs were compared directly. With an average contribution margin I per DRG case and inpatient day of $€ 448.28$ and given the capacity constraint "inpatient days", caesarean sections for neonates with a gestational age of more than 33 weeks and without complicating diagnoses (DRG O01F) were more profitable than vaginal births without complicating diagnoses (DRG O60D), which had a contribution margin of $€$ 416.56. In comparison, caesarean sections for premature babies until the end of the 25th week of gestation (DRG O01A: $€$ 193) were economically less profitable than vaginal deliveries with complicating OR procedures until the end of the 33rd week of gestation (DRG 002A: $€ 535.39$ ) or vaginal deliveries with at least one serious complicated diagnosis until the end of the 33rd gestation week (DRG O60A: $€$ 454.18). With an average contribution margin I per DRG case per inpatient day of $€ 448.28$, DRG O01F (caesarean section without complicating diagnosis $>33$ weeks of gestation) is, from an obstetric point of view, the only c-section DRG which is more profitable than the individual DRGs for vaginal deliveries.

The economic disadvantages of c-section DRGs compared to vaginal births are shown in model E. In this model, all bed occupancy rates which were used in the real model for birth-related DRGs (83.76\%) were evenly distributed (13.96\%) across the 6 different c-section DRGs, and all other percentages of total inpatient hospital days of the remaining non birth-related DRGs compared to the calculation for 2009 were left unchanged. If a bed occupancy rate of $100 \%$ was assumed in model E, this resulted in an operating loss of $€-75948.71$, which was lower than the operating result of model J by $€ 1280935.53$. In model J, all bed occupancy rates for birth-related DRGs were evenly redistributed (20.94\%) across vaginal births DRGs (DRGs O60A-D). If exclusively vaginal deliveries with complicating OR procedures were posited, with a respective share of $41.88 \%$ in the capacity constraint "inpatient days" (DRG 002A/B), then the operating profit could even be increased to $€ 3133122.76$ as shown in model N.

Schwenzer et al. [22] also came to the conclusion that in Germany caesarean sections brought no economic benefit compared to vaginal deliveries. Focussing on elective c-sections was only economically profitable if a birth clinic or perinatal centre carried out c-sections only at certain times, as this reduced or eliminated on-call costs [22]. Despite the appeal of the additional revenues generated by c-sections it is important to remember the higher costs involved. Moreover, it must be remembered that if the rate of c-sections is increased, this will increase the costs of the remaining vaginal births as the on-call costs have to be distributed across fewer vaginal births.

Seelbach-Göbel [13] showed that a level I perinatal centre covers its actual costs predominantly by the revenues generated by spontaneous births (DRG O60D) and would have an operating loss without them. The actual costs of vaginal births for the DRGs O60B ( $€ 123$ ), O60C ( $€$ 194) and O60D ( $€ 246$ ) are below the target costs in the InEK calculation. In contrast, the actual costs of csections were far from covered by the InEK calculation. The shortfalls are shown below with operating losses characterised by a negative sign. The costs of premature births (O01A: $€-2992$, O01B: $€-626)$, births with several complicating diagnoses (O01C: $€-846$, O01D: $€-343$ ) and c-sections after the end of the 33rd week of gestation (O01E: $€-332$, O01F: $€-233$ ) were not covered. This means that in a level I perinatal centre the costs of complicated vaginal births before the 33rd gestational week (O02A: $€-398$, O60A: $€-1059)$ and the costs of vaginal deliveries with complicating OR procedures after the 33rd week of gestation (O02B: $€-96$ ) could not be covered according to the costs calculated by InEK [13]. However, in contrast to our study, Seelbach-Göbel only included DRGs which ended with the birth of the child. Thus, the remaining costs of in-hospital stays during pregnancy were not included. When the real costs of university hospitals were compared with the InEK calculation, only the costs of DRG O60D were covered. All other birth-related DRGs in university hospitals resulted in quite substantial losses [13].

An analysis of published reports for other countries comparing the costs of the different types of births came to interesting results [22]. Henderson and colleagues [26] published a review article where they summarised and analysed 49 international papers with regard to the costs of vaginal deliveries without complications and c-sections. The studies significantly showed that, on average, c-sections were more expensive than vaginal births. The cost of a spontaneous birth without complications was between $£ 629$ and $£ 1298$, while the costs of c-sections were significantly higher, ranging from $£ 1238$ to $£ 3551$.

In their analysis, Kazandjian et al. [27] came to the conclusion that c-sections are not always more expensive than vaginal deliveries. They viewed the perinatal centre as an interdependent eco- 
nomic unit and included the costs of treating neonates in addition to birth mode-related costs. The average cost for mother and child after a vaginal delivery, including the costs of the neonatal intensive care unit, was thus $\$ 17624.38$ while the costs after a c-section were only $\$ 13805.47$. If the costs of the neonatal intensive care unit were not included, the cost of a c-section was $\$ 7529$ and the cost of a vaginal delivery was $\$ 5012.80$.

Seelbach-Göbel [13] showed that in the current DRG system complicated cases are not adequately remunerated. This issue, which has far-reaching consequences for level I perinatal centres, was analysed in the theoretical models B and L. The models showed that from a purely economic standpoint it was better to offer care to as few high-risk pregnancies as possible and instead to provide services for pregnancies without associated pathologies.

Because of the current discussion about the minimum number of cases perinatal centres need to treat when caring for premature babies and very low birth weight neonates, it should be noted that some theoretical models are not easily compatible with maintaining the centre's status as a level I perinatal centre. This particularly applies to models A and L, in which either no births were possible or all pathological pregnancies were excluded. Maintaining the current status of the UPF was also questionable in the theoretical models $\mathrm{C}, \mathrm{D}, \mathrm{F}$ and $\mathrm{H}$; in these models enough extremely low birth weight neonates were born but they were not treated; instead they were transferred to other hospitals. In contrast, if the case mixes of the models I and $\mathrm{K}$ are used, the required case numbers of very low birth weight neonates will not be achieved.

Based on our results, it would make more sense for certain hospitals to pursue a classification as a level III or IV perinatal centre rather than as a level I or II. But it must be emphasised that such reflections could jeopardise the comprehensive coverage of high level perinatal centres. Offering additional incentives such as supplementary payments or similar might be advisable from a health economic perspective.

From a purely economic perspective, it might be expedient to downgrade a perinatal centre as this would reduce labour costs. This aspect was not factored into the theoretical models described here. The fact that changes to the range of services and treatments provided would result in the partial or entire closure of certain cost centres was also not included in our calculations. For the purposes of simplification it was assumed that costs would be completely redistributed across other cost centres. Thus, the theoretical models do not depict real scenarios; they are theoretical marginal models which help increase the awareness of certain economic aspects of healthcare. A good knowledge of marketing and marketing strategies will be necessary if changes in services and treatments are implemented. Lux et al. [16] showed how many multilayered and complex the factors influencing patients' choice of hospital are. If the management of a hospital does not adapt its strategies and planning over the longer term to the wishes of patients, operating profits could easily tip over into operating losses.

The theoretical models described here are sure to prompt much discussion and they have certain additional limitations. As the theoretical models are all based on the results calculated for the real operating profit of the UPF in 2009, the limitations and particularities of the UPF also apply to the theoretical models. It should also be noted that the validity of some of the contribution margins I used here may limited due to the low number of cases. Because of such variations, theoretical models cannot provide a comprehensive financial picture. However, this is not the aim of these theoretical models; the depiction of marginal cases contributes to economic thinking and decision-making.

Because the paediatric department was not included in the calculations and because obstetrics involve a very special type of patient, only limited conclusions on the economic aspects of contribution margins can be drawn from this study. The question arises whether examining the economic aspects of the care of premature babies, neonates and their mothers and drawing conclusions based on economic considerations alone is ethically defensible. Differentiating between "profitable" and "less profitable" DRGs is not desirable, neither medically nor ethically, as this differentiation focuses only on economic goals. In the theoretical models discussed here, all ethical, medical and structural aspects and requirements were subordinated to economic issues.

As level I perinatal centres are tertiary care centres, they are not permitted to refuse any cases. When considering the range of services provided by a centre, it should be remembered that in obstetrics the extent and type of treatment which may be required cannot usually be planned ahead. Thus, when a patient is admitted to hospital, it will not necessarily be immediately clear which DRG will be used for the patient and her newborn baby at discharge.

Moreover it would also be necessary to study whether, when the bed occupancy rate is $100 \%$, the fixed costs would also be higher than that cited in the calculation of the UPF's operating result in 2009. In principle, fixed costs (such as personnel costs) only increase if total capacity is increased. But in view of the fact that employee resources are already spread quite thinly it is questionable whether patients and their newborns could still be adequately cared for if the department is continually working to full capacity. In our calculations we therefore assumed that the fixed costs would change depending on whether bed occupancy rates were higher or lower. To simplify matters in our calculations, it was assumed that changes in fixed costs occurred progressively and not stepwise.

The validity of our theoretical models can currently not be verified against other comparable models for German perinatal centres. Additional analysis, particularly for perinatal centres providing other levels of care (levels II, III and IV), will also be necessary.

\section{Conclusion}

$\nabla$

The theoretical models developed in this study highlight the potential consequences for planning and regulating case numbers and services of perinatal centres.

The question about the financial viability of perinatal centres cannot be answered with absolute certainty. While the results of the calculation of UPF's operating result in 2009 indicate that level I perinatal centres can currently generate an operating profit if bed occupancy rates are high and the case mix is profitable, theoretical models also highlighted a number of loss-making factors which could quickly threaten the continued existence of a level I perinatal centre. The study has once again emphasised the importance of efficiently managing these centres.

\section{Conflict of Interest \\ $\nabla$}

There is no conflict of interest. 


\section{References}

1 Lohmann $\mathrm{H}$. Erfolgsfaktor Medizin: Anforderungen an ein modernes Krankenhausmanagement. Berlin, Heidelberg: Springer-Verlag; 2009: 3-14

2 Beckmann MW, Bader W, Bechtold I et al. Finanzierung und finanzielle Probleme von Leistungen und Strukturen im Fachgebiet Gynäkologie und Geburtshilfe im Jahr 2011 - allgemeine Aspekte und geburtshilfliche Versorgung. Geburtsh Frauenheilk 2011; 71: 367-380

3 Lux MP, Fasching PA, Loehberg CR et al. Health services research and health economy - quality care training in gynaecology, with focus on gynaecological oncology. Geburtsh Frauenheilk 2011; 71: 1046-1055

4 Gemeinsamer Bundesausschuss. Vereinbarung des Gemeinsamen Bundesausschusses über Maßnahmen zur Qualitätssicherung der Versorgung von Früh- und Neugeborenen vom 20. September 2005, zuletzt geändert am 20.08.2009. Bundesanzeiger; 2009: 4450

5 Zapp W, Oswald J. Controlling-Instrumente für Krankenhäuser. Stuttgart: W. Kohlhammer GmbH; 2009: 17-288

6 Krämer N. Strategisches Kostenmanagement im Krankenhaus, Anwendung unter besonderer Berücksichtigung von DRG-Fallpauschalen. In: Schriftenreihe Gesundheitsmanagement und Medizinökonomie. Hamburg: Verlag Dr. Kovač; 2009: 1-172

7 Leititis JU. Rationalisierungsinstrument mit Nebenwirkungen, Ökonomische und medizinische Spannungsfelder beim Einsatz vollpauschalierter Vergütungen. Forum für Gesellschaftspolitik; 2000: 194-197

8 Goedereis $K$. Einfluss auf die Versorgungslandschaft. In: Rau F, Roeder $\mathrm{N}$, Hensen P, Hrsg. Auswirkungen der DRG-Einführung in Deutschland, Standortbestimmung und Perspektiven. Stuttgart: W. Kohlhammer GmbH; 2009: 239-253

9 Foit K, Vera A. Anreizorientierte Krankenhausvergütung mit Fallpauschalen. Gesundheitsökonomie und Qualitätsmanagement 2006; 11: 245-251

10 Lehnen H, Mosblech N, Reineke T et al. Prenatal clinical assessment of sFlt-1 (soluble fms-like tyrosine kinase-1)/PIGF (placental growth factor) ratio as a diagnostic tool for preeclampsia, pregnancy-induced hypertension, and proteinuria. Geburtsh Frauenheilk 2013; 73: 440-445

11 Reinhard J, Hanker L, Sänger $N$ et al. Neonatal transfer rate and mode of delivery from 37th week of gestation in a German perinatal center level 1. Geburtsh Frauenheilk 2013; 73: 324-329

12 Lux MP, Kraml F, Wagner S et al. Financial viability of perinatal centers in the longer term, taking legislative requirements into account? An examination of the cost-revenue structure of a level I perinatal center. In vivo 2013; in press
13 Seelbach-Göbel B. Struktur und Refinanzierung in der Geburtshilfe Trägt sich die Geburt im Perinatalzentrum Level I? Z Geburtsh Neonatol 2010; 214: 198-204

14 Schmidt S. Refinanzierung der Geburtshilfe. Z Geburtshilfe Neonatol 2010; 214: 175-176

15 Lux MP, Fasching PA, Bani M et al. Marketing von Brust- und Perinatalzentren - Sind Patientinnen mit dem Produkt „zertifiziertes Zentrum“ vertraut?. Geburtsh Frauenheilk 2009; 69: 321-327

16 Lux MP, Fasching PA, Schrauder M et al. The era of centers: the influence of establishing specialized centers on patients' choice of hospital. Arch Gynecol Obstet 2011; 283: 559-568

17 Euro-Peristat. European perinatal health report. Luxemburg, 2008. www.europeristat.com; last access: 15.06.2011

18 Hornemann A, Bohlmann MK, Altgassen C et al. Primäre Sectiones subventionieren Spontangeburten, Spielen finanzielle Interessen bei der steigenden Sectiorate eine Rolle? Geburtsh Frauenheilk 2008; 68: 1082-1088

19 Hornemann A, Bohlmann MK, Thill M et al. Ökonomie der Geburtshilfe - Primäre Sektio versus Spontanpartus - Bilanz der aktuellen Vergütung im G-DRG-System. Geburtsh Frauenheilk 2008; 68: 520

20 Feige A. „Heute sparen, morgen besser steuern“, Kritische Anmerkungen zu den Auswirkungen der Sparmaßnahmen auf pränatal-/geburtsmedizinische Leistungen. Z Geburtsh Neonatol 2010; 214: 177-179

21 Heer IM, Kahlert S, Rummel S et al. Hospital treatment, is it affordable? A structured cost analysis of vaginal deliveries and planned caesarean sections. Eur J Med Res 2009; 14: 502-506

22 Schwenzer T, Schwenzer C. Kosten und Erlöse für eine Geburt in Deutschland, Eine Analyse auf der Basis der Daten des Instituts für das Entgeltsystem im Krankenhaus (InEK). Z Geburtshilfe Neonatol 2010; 214: 188-197

23 Ecker JL, Frigoletto jr. FD. Cesarean delivery and the risk-benefit calculus. N Engl J Med 2007; 356: 885-888

24 OECD. Gesundheit auf einen Blick 2009: OECD Indikatoren. OECD Publishing; 2010: 87-110

25 FHF - Fédération hospitalière de France. Étude sur les césariennes. Paris, 2008. www.fhf.fr; last access: 03.03.2011

26 Henderson J, McCandlish R, Kumiega L et al. Systematic review of economic aspects of alternative modes of delivery. BJOG 2001; 108: 149157

27 Kazandjian VA, Chaulk CP, Ogunbo S et al. Does a Cesarean section delivery always cost more than a vaginal delivery? J Eval Clin Pract 2007; 13: $16-20$

Deutschsprachige Zusatzinformationen online abrufbar unter: www.thieme-connect.de/ejournals/toc/gebfra. 